\title{
Research for Maintaining Cross-Strait Peace and Economic Development in the Post-Epidemic Era
}

\author{
Hung-Chi Hsu ${ }^{1}$ Hui-Lin Hsu ${ }^{2}$ Mei-Zhen $\mathrm{He}^{3 *}$
}

\author{
${ }^{1}$ School of Business Administration, Baise University, Guangxi 533000, China \\ ${ }^{2}$ School of Business Administration, Baise University, Guangxi 533000, China \\ ${ }^{3}$ School of Business Administration, Guangxi University of Finance and Economics, Guangxi 53003, China \\ *Corresponding author. Email: $3264261493 @ q q . c o m$
}

\begin{abstract}
The study based on the post-COVID-19 epidemic era to analyses the confusing international economic situation. The article studies the contradictions and antagonisms of the United States, China and Taiwan, and explores the best interests of cross-strait relations through a model of competition and cooperation. On the basis of the guidance of social forces, promote the economic development and peace maintenance of both sides of the strait. The results of this study suggest that peaceful cross-strait relations should be guided by social forces and integrate non-governmental forces to create cross-strait economic development. The cross-strait should take non-governmental academic exchanges as the main body to create cultural integration, promote local government-level communication for mutual visits and learning, and reduce differences between each other. People on both sides of the strait should work together to make contributions for the rejuvenation of the great Chinese nation.
\end{abstract}

Keywords: cross-strait peaceful relations, cross-strait economic and trade development, social forces

\section{INTRODUCTION}

The pursuit of peace and economic development is a product of today's globalization, and it is also a trend that guides world development. Cross-strait relations have long-term remarkable historical and highly political complexity and are dragged and restricted by many uncertain factors in international relations' pulsation. In the conflict of various interests and the interdependence of national, the two sides of the Strait develop and coexist peacefully. The relationship of mutual prosperity and interconnection has always been the only way and the greatest common divisor which supported by the people on both sides of the Strait.

\section{CURRENT ECONOMIC SITUATION ACROSS THE STRAITS IN THE POST- EPIDEMIC ERA}

\subsection{Domestic Economic Situation}

The trade war between China and the United States and the new crown pneumonia epidemic have brought a double blow to China. President $\mathrm{Xi}$ Jinping has repeatedly mentioned the terms "internal circulation" and "double circulation" in several meetings. The mutual promotion of international double cycles to develop China's new economic structure fully demonstrates that China has the responsibility and willingness to share the results of economic growth with the world while integrating into globalization. However, during special events or particular phases, China should pay more focus on the expanding, domestic demand and economic cycles which supporting the domestic self-supply and demand potentially, and achieving the goal of economic growth.

After China completed the task of resisting the financial crisis in 2010, its annual economic growth rate has been brilliant with a double-digit growth rate. It is a glorious era of China's rapid growth, but the following two years have been affected by the global economic decline. The rate fell below $8 \%$, and then slowly fell below $7 \%$ in the following three years. Nevertheless, after 2010 the per capita income has exceeded US $\$ 4,000$, and it firmly establishes as a middle-income nation in the world. From the second half of 2015 to the first half of 2018 , the economic growth rate maintained in a narrow range of $6.7 \%$ to $6.9 \%$ with growth slowly, but the slowly growth rate was lasted for 12 quarters. Until 2019, the impact of the epidemic and the U.S. negotiations and restrictions on trade caused the growth rate of 2019 to drop to $6.1 \%$. By the fourth quarter of the epidemic, it has 
even fallen to the critical point of maintaining $6 \%$. In 2020, the new crown pneumonia epidemic gradually expanded, and the international epidemic was also in the ascendant, the U.S. launched the trade war, then joined the science and technology war to suppress China's economic growth. Fortunately, President Xi's strategy and the efforts of all the people make the economic growth returned to the expected performance in the first half year of 2020 .

\subsection{Cross-strait Economic Situation}

Under the rule of the Democratic Progressive Party in Taiwan, cross-strait relations have become estranged gradually, however ' the exchanges between the people and the society have not decreased but increased. It is evident that the exchanges of individuals and enterprises, including various social organizations and groups, are not stop caused by political difficulties. After the outbreak of the new crown pneumonia epidemic in 2020 , countries have adopted lock-in policies to contain the expansion of the epidemic, but it has not slowed down the cross-strait economic and trade development. According to the foreign trade data released by the Mainland Customs Administration in July of 2020, the import and export trade amount between the two sides of the Strait were 112.67 billion U.S. dollars in the first half of this year, which is an increase of $7.8 \%$ compared with the same period. Among them, mainland China's total export value to Taiwan was 27.42 billion U.S. dollars, which also increased by $7.9 \%$ compared with the same period. The total export value of Taiwan to the mainland was 85.25 billion U.S. dollars, compared with an increase of $7.7 \%$ over the same period. Taiwan's trade surplus with the mainland exceeded US $\$ 57.8$ billion [1]. The above data clearly shows that the external tensions on both sides of the Strait, but non-governmental exchanges and the trades are still heating up. Cross-Strait relations are closely interdependent.

\section{THE CROSS-STRAIT RELATIONS HAVE CHANGED DRAMATICALLY UNDER THE U.S. - CHINA COLD WAR}

\subsection{Tripartite relationship: China, USA and Taiwan}

After the rise of mainland China and its entry into the power stage of world, how to build a new form of relationship between China and the United States has always been the focus of discussion in recent years. Recently as China-US relations have undergone tremendous changes, the new term "new cold war" has become a new perspective for the world to interpret the relationship. However, we must discuss that the so-called "new cold war" is an alternative cold war, which is entirely different from the cold war in the arms race between the United States and the Soviet Union in the past. The first, after the Second World War, the United States and its allies formed NATO had a half-century political confrontation with the communist countries headed by the Soviet Union.

At that time, two camps confront globally, but there are not two systems now. As the current situation concern, the future situation should not be similar to that of the US-Soviet cold war. The second, the intensity and connection of the economic and trade interaction between China and the United States are far better than the arms race relations between the U.S. and the Soviet Union at that time. The relationship between China and the United States is not a purely political competition, but is a cooperation relationship with strong economic and trade links. Furthermore, from the observation of the political and diplomatic of the global and the reactions of the E.U., Japan, and other countries to the competition between China and the United States, the so-called new cold war between China and the United States can be said to be a country-to-country cold war relationship only, rather than a camp confrontation that extends to the international system.

After the DPP came to power, Taiwan has adopted a gradual alienated approach to cross-strait dialogue and exchanges. At the same time, it has also tried its best to obstruct cross-strait economic and social interactions. Especially after the outbreak of the new crown pneumonia, the Sino-U.S. relationship entering a new Cold War situation coupled with the U.S. support for Taiwan, resulting the interaction between the two sides of the strait to become more alienated. The situation between the two sides of the Strait become highly tense.

On April 29, 2005, Mr. Hu Jintao and Mr. Lien Zhan jointly issued the "Common Vision for Peaceful Development across the Straits" after a Beijing meeting. They proposed that Cross-strait adhere to the "1992 Consensus", seek peace and stability across the Taiwan Strait. For decades, cross-strait relations have promoted peacefully coexistence on this platform. Peaceful development is also the value judgment and essential goal of the people in the development of cross-strait relations, and it is also a universal value recognized by human society. The current cross-strait relations under the DPP party in power are so rigid and cannot reverse. At present, it is challenging to obtain relief and solutions through the top-down approach. Both sides of the Strait must seek other ways to break the deadlock.

\subsection{The cross-strait economy is affected by the US-China trade war}

\subsubsection{Economic growth continues to increase across the strait}

The global economy has severely strike by COVID19. The countries where the epidemic has slowed are 
moving towards unblocking and gradually returning to average economic production. Compared with other regions, Taiwan's epidemic control is better than in other areas. Taiwan economic forecast remains optimistic for 2020, but it differs from international forecast. As shown in Figure 1, Some Taiwan research institutes have an opinion on the 2020 economy. Compared to the estimated economic growth rate of International Monetary Fund (IMF) is $-4 \%$ for Taiwan. Internal economic outlook of Taiwan is optimistic.

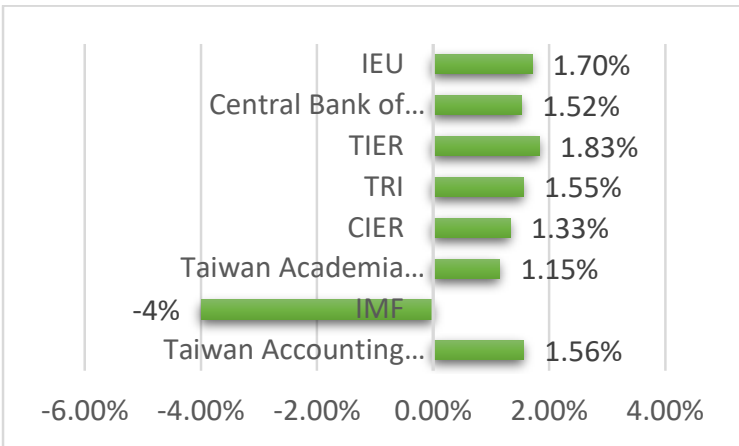

Figure 1 Taiwan Economic Growth Forecast in 2020

The Taiwan government and scholars are full of optimism about the economic climate, but some doubts and variables cannot ignore. According to the statistics from Taiwan's Comptroller and Accounting Office, the economic growth rate in the first quarter of 2020 was $2.2 \%$, and in the second quarter was $-0.58 \%$. It shows that the epidemic has had a very negative effect on the economy. From another perspective, the economic countermeasures lights of Taiwan continue to show the downturn in yellow and blue lights in the first quarter of 2020; Taiwan is an island-based economy with scarce resources. Materials need to be supplied by import. Under the global environment of low-interest rates, low growth, and low inflation, Taiwan's internal significant demand is insufficient. Most companies have a conservative attitude towards investment and the private sector tends to reduce expenditures consumption. Therefore, the growth momentum of Taiwan economy mainly comes from the surplus in foreign trade. As shown in Figure 2, the proportions of various sectors in Taiwan GDP structure from 2009 to 2019 show that exports of goods and services for the highest GDP structure [2].

\section{$100.00 \%$}

$0.00 \%$
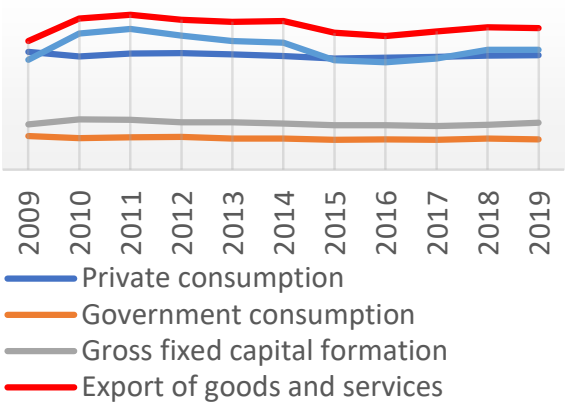

Figure2 2009-2019 Taiwan GDP Structure Trend

In the first half of 2020, the COVID-19 was raging, and all countries exports were fell down sharply. However, Taiwan exports in the first half of 2020 still grew by $0.5 \%$, and its export performance was outstanding. As shown in Figure 3, only Taiwan exports maintained positive growth compared with major regions. The impact of Taiwan exports by the epidemic is relatively mild. The exports are the primary source of Taiwan's GDP growth. If analyze the export regions, the mainland and Hong Kong are still the primary sources of Taiwan's imports and exports. Figure 4 shows that crossstrait trade exchanges become tighter and closer even if affected by the global epidemic and even after the DPP deliberately adopted political decoupling. In summary, various data show that Taiwan economic development is highly relate to mainland. The dependence is relatively high, and if decoupling, it will have adverse effects on each other.

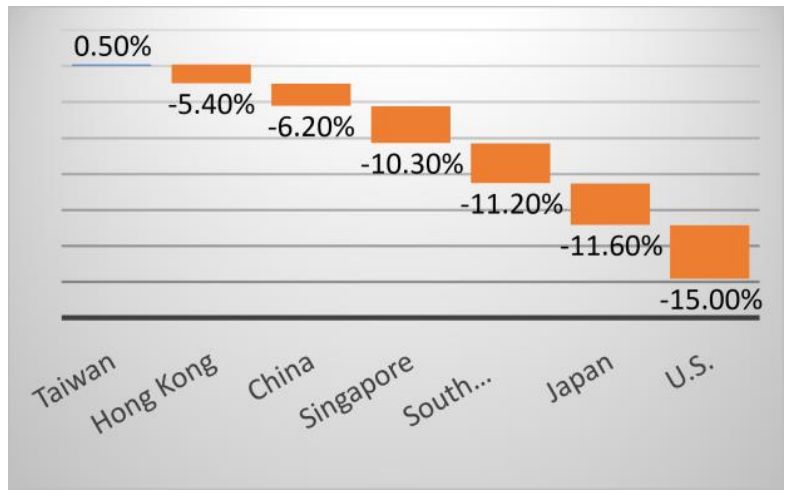

Figure 3 Changes in the Export Growth Rate in the First Half of 2020 


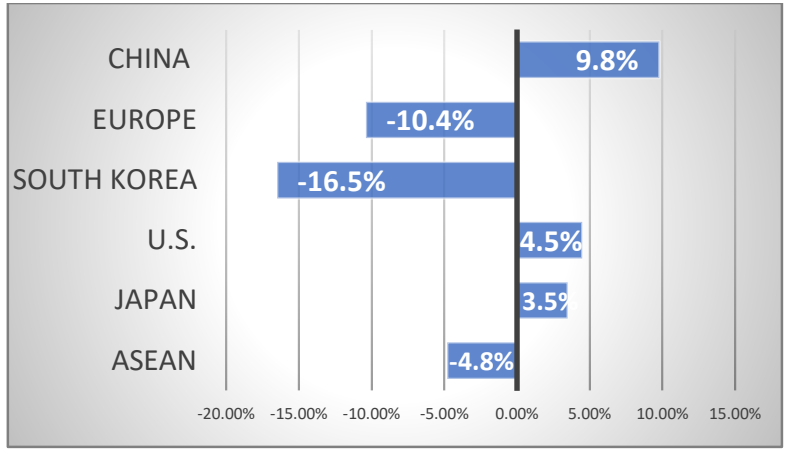

Figure 4 Taiwan Export to Major Markets in the First Half of 2020

\subsubsection{Taiwan economic development layout in the post-epidemic era}

Moving towards the post-epidemic era, it expects that under the influence of loose policies and funds, the global economy will gradually recover. However, the profitability of enterprises will still be affected by political and economic factors at domestic and abroad, plus the epidemic and China-U.S. trade war are also full of uncertain challenges, which will still cause companies to face extreme and unpredictable volatility in their profits. According to the latest World Economic Outlook Report released by the International Monetary Fund (IMF) in June [3], the estimated global economic growth rate in 2020 is $-4.9 \%$, which is $1.9 \%$ lower than the forecast in April this year, as shown in Figure 5. China economic growth rate can remain positive this year; however, most countries economic growth rate will turn from positive to negative. The reason is that the IMF judges that the COVID-19 impact on economic activities in 2020 is more than expected. As serious, it judges that the road to recovery will be slower than previously predicted. The IMF forecasts pessimistically that the global economic growth rate will revise downward. Simultaneously, the IMF report also takes a cautious view on the global economic outlook in 2021 and considers that the global economic growth rate is only $5.4 \%$. Taiwan belongs to an Island economy, in which the mainland and Hong Kong are the major import and export objects. Naturally, cross-strait relations are not immune to the fluctuations of global factors.

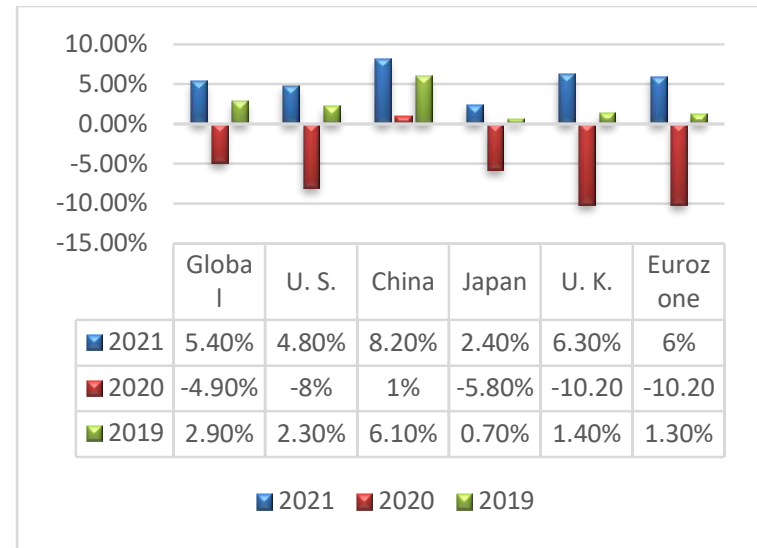

Figure 5 IMF Estimates for the Economic Growth Rate of Major Countries

The global village concept collapsed with the fever of the epidemic. Countries have adopted border blockade policies to reduce overseas infections. It has further catalyzed the already tense political situation. Besides, the confrontation between China and the United States has increased. The bilateral conflict will force countries to "choose sides" to safeguard their interests. Countries must also express their support for one of them while weighing their interests. However, for Taiwan in the awkward situation of confrontation between the United States and China, maintaining a balance will be the best option, especially when global economic growth is moving to Asia. As shown in Figure 6, from 1995 onwards to 2020, the total economic growth of North America, Europe and Japan has gradually decreased from $53 \%$ to $33 \%$, while the total economic growth of Asia (except Japan) has increased from 20\% to $40 \%$ after 15 years of hard work. The golden cross-time period is in 2018. Among them, China is the most significant growth and appreciation in Asia. For the reason that Taiwan should layout in Asia in the post-epidemic era, especially in China.

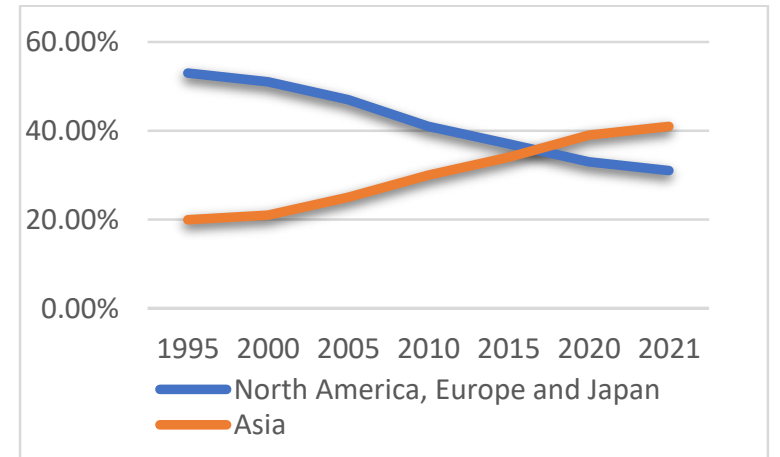

Figure 6 1995-2020 Regional Economic Growth as the Percentage of Global GDP 


\section{THE PEACEFUL CROSS-STRAIT RELATIONS IS HARD TO OBTAIN}

\subsection{The expectations of the people on cross- strait}

COVID-19 is the largest black-swan in 2020. It has severely damaged the global economy, trade, and investment. It is a crisis and a turning point for the industry [4]. The current cross-strait connections are interrupted, especially under the new cold-war relation of China-US. Misjudgments or ambiguous attitudes are prone to confuse the original thinking. In the absence of sufficient ability to distinguish, maintaining the status quo is the best choice. The public opinion on both sides of the Strait for a long time is that both insist on crossstrait peace without conflict, smooth exchanges without isolation and communication and cooperation without zero-sum confrontation. Many Taiwanese eagerly believe that economic development is the priority. They don't want cross-strait relations to be affected due to the turmoil of international factors

\subsection{An excellent model of cross-strait exchanges}

Both sides of the Strait should expand the scope of peaceful relations to the entire society, such as solving economic, cultural, and livelihood issues. For example, the Twin Cities Forum co-created by Shanghai and Taipei for 11 years since 2010. Based on mutual trust between the both sides, the two cities have worked hard to overcome various difficulties, continue to communicate, and accumulate mutual goodwill. This is the best example of the positive relationship. Even if the COVID-19 hits it in 2020, the exchanges were not stop. It demonstrates the determination and goodwill of the two parties to continue to communicate. Shanghai and Taipei shared and learned from each other, especially for the industrial and economic development issues. Both sides of the strait work together to pursue peaceful development. As Taipei Mayor Mr. Ke Wenzhe said at the forum: The attitude of handling cross-strait affairs is "pragmatic". Cross-strait exchanges are better than breaking, cooperation is better than confrontation, and goodwill is better than enmity. After all, the history and culture of the two sides are connected. Although there is still a deadlock between the two sides. Both should jointly pursue the peaceful development through communication and dialogue.

The Twin Cities Forum started in 2010. After many storms and disturbances, both parties did not retreat. Instead, both insisted on overcoming difficulties and held it. Through the Twin Cities Forum's holding, the two sides of the Strait continue to communicate based on mutual trust which will help cross-strait relations develop in a positive direction.
The Twin Cities Forum has achieved excellent results. The both signed 36 memorandums of cooperation. Although affected by the COVID-19 in this year, both personnel unable to communicate face-to-face. After Taipei and Shanghai reached a consensus, Twin Cities Forum was handled by online in 2020 . These demonstrate the goodwill and determination of continuous communication with each other.

\section{CONCLUSION}

The relationship between the two sides of the Taiwan Strait is intimate and contradictory, with both antagonistic and competing contradictions coexisting. However, economic and trade relations have always been the most active between the cross-strait. Therefore, the complexity of cross-strait relations is unable to portray from a political perspective only. The development of cross-strait relations should be inspected in a multidimensional manner to deepen communication.

In the post-epidemic era, restoring the foundation of mutual trust is the key to economic revitalization, which has Significant meaning for cross-strait economic and trade integration [5]. For example, the policy for Taiwanese return to the mainland to visit their relatives, Taiwan businessmen invest in mainland, and the provincial and municipal governments in the mainland have successively introduced various policies to encourage and guarantee the safety of Taiwanese investment, etc. All of which are social forces deepens cross-strait exchanges and integration. Therefore, through dialogue and exchanges at various levels of society, it acts as a lubricant for deepening integration of cross-strait relations, meanwhile, it also becomes a positive driving force for the peaceful development. Simultaneously, socialized communication has the advantages of broadness, creativity, acceptability, and sustainability and reflects the great feeling of the Chinese rejuvenation. Based on social forces, the specific approach for promoting the peaceful development and creating a double-win situation is as followings:

\subsection{Based on unofficial forces}

Under the current political situation, the possibility of direct official cooperation is low. Therefore, the role of non-governmental forces is very important and has become the mainstream force for cross-strait exchanges. For example, the various preferential policies issued by the mainland encourage people on actively exchange and visits with unofficial organizations. Finally, a seamless integration of two cultures will be achieved.

\subsection{Give priority to economic development}

Over the past 30 years, economic growth has been a vital driving force in developing cross-strait relations. How to ensure the safety and convenience of Taiwanese 
investment in the mainland has become an essential factor for cross-strait Integration. Using economic interests as the mediators have prompted the Taiwan government to develop cross-strait relations with more open attitude.

\subsection{Establish a mechanism for communication and cooperation}

With non-governmental economic organizations as the channel, both organize various economic cooperation seminars, forums, or seminars to create a platform for cross-strait information of investment and opportunities of business. More, it will encourage enterprises on both sides of the Strait to sign more economic cooperation agreements to create mutual prosperity.

\subsection{Academic exchanges create bridges for cultural integration}

There are many visits and exchanges between mainland and Taiwan universities every year, including teachers from different universities and short-term student exchanges. Now Taiwan and the mainland have mutually recognized academic qualifications, and recruit university students through each other. The integration and introduction of high-level talents eliminate the barriers between each other and become a bridge for development and integration of cross-strait.

\subsection{Communication through the local government level}

Both should promote mutual visits and exchanges actively at local governments levels, such as sister cities, forums and regularly exchanges and visits in various meetings. For example, the Cross-Strait City Forum of
Taipei and Shanghai is on the way of the best model to peaceful cross-strait development. This successful model must promote to other cities, such as Guangxi and Hualien, which is the best combination of two cities in geographical location and humanities.

Looking into the current situation and looking forward to the future, the world situation after COVID19 is unpredictable, but the fate of the Chinese on both sides of the Taiwan Strait is closely linked because of the common national sentiment and culture. Rejuvenating the great Chinese nation is the responsibility of this generation.

\section{REFERENCES}

[1] Source: Statistics from the General Administration of Customs of the People's Republic of China http://www.customs.gov.cn/customs/302249/30227 4/302275/index.html.

[2] Source: The latest statistics of the Taiwan Accounting Office. https://www.dgbas.gov.tw/pointlist.asp.

[3] Source: International Monetary Fund Chinese website, World Economic Outlook Report (2020.06).

https://www.imf.org/external/chinese/index.htm.

[4] Yang Shu-fei (2020). Global industry and economic trends in the post-epidemic era and the complementary strategies of enterprises. Economic Outlook Bimonthly, (191), 35-41.

[5] Li Chun (2020). The impact of new coronary pneumonia on regional integration and how to respond: Take CPTPP as an example. Economic outlook Bimonthly (190), 88-92. 